\title{
LA DISPUTA POR LOS CORREDORES DE MOVILIDAD EN LA DÉCADA DE LOS NOVENTA: REFLEXIONES SOBRE EL CONFLICTO ARMADO INTERNO COLOMBIANO
}

\author{
Mayor General. (RA) LUIS IGNACIO BARÓN CASAS ${ }^{l}$
}

\section{INTRODUCCIÓN}

Después de tantas experiencias vividas como piloto de la Fuerza Aérea Colombiana surgen reflexiones sobre las dinámicas del conflicto armado interno, y de los planes violentos desarrollados por los grupos armados ilegales para obtener sus propósitos. En este documento, presento una reflexión sobre el conflicto armado que se vivió en el país en la década de los años noventa, centrando la atención en dos variables que, a mi parecer, resultan totalmente explicativas en la transformación del contexto de seguridad que el país experimentó.

Con la primera variable se indilga a las dinámicas desarrolladas por las FARC para cercar a Bogotá y tomarse el poder; se tratan de unas dinámicas territoriales en las que esta organización desplegó una guerra de movimientos, encaminada a concentrar gran número de hombres en puntos clave de la geografía nacional. Por supuesto, esto implicó una respuesta contundente de las Fuerzas Militares, quienes contrarrestaron la ofensiva, y transformaron completamente los indicadores de seguridad del país.

La segunda variable que me interesa desarrollar centra su atención en las transformaciones de las políticas, agendas y compromisos de seguridad en las 4 figuras presidenciales que tuvo el país en esa década. La tesis es muy sencilla: las Fuerzas Militares no podían dar importantes avances en el terreno militar, si no contaban con el apoyo claro y contundente del aparato gubernamental, es decir, que el problema de seguridad no obedece exclusivamente a las instituciones militares, sino que debe ser entendida como una política de Estado, que comprometa a distintas instituciones del mismo.

Los criterios para seleccionar la década de los años noventa como período de estudio obedece a dos criterios puntuales: en primer lugar, porque es la década

Mayor General. Ex segundo Comandante y Ex Jefe de Estado Mayor de la Fuerza Aérea Colombiana. 
en la que se presentan los más altos índices de violencia por cuenta del actual conflicto armado, tal y como lo documentan las estadísticas oficiales o diferentes informes académicos que se reseñarán más adelante.

La segunda, porque en esta década hay unas transformaciones operacionales muy importantes al interior de la Fuerza Aérea Colombiana, que le llevan a asumir progresivamente mayor contundencia y precisión en sus operaciones, y mayor incidencia en la disminución de la intensidad del conflicto. En este período de tiempo la Institución arroja resultados operacionales óptimos, y genera operaciones decisivas y fundamentales para truncar los planes trazados por las FARC (MARÍn et al., 2016).

Estas dos variables que sustentan y guían esta reflexión, permiten esbozar una serie de conclusiones sobre por qué se intensificó el conflicto en unos años específicos (expresado en un aumento de las tomas violentas a municipios, o el incremento del secuestro, entre otros); pero también, porque se lograron configurar mejores estadísticas en materia de seguridad al final de la década de los años noventa (EcHANDÍA, Camilo, 2011).

\section{Dinámicas territoriales del conflicto armado}

En un reciente libro publicado por la Fuerza Aérea Colombiana fui consultado sobre las dinámicas de seguridad en el departamento de Antioquia (Marín et al. 2016), allí señalé que la concentración de la violencia en unos municipios estaba relacionada con el interes de las FARC por asegurarse un corredor de movilidad que le permitiera conectar al norte con el sur del país, en inmediaciones de la capital de la República.

\footnotetext{
"crear corredores que permitian la comunicación efectiva entre el sur y el norte del pais, y entre el occidente y el oriente. Por su posición, Antioquia conectaba al Atlántico con la antigua 'zona de distención'; a través de las vías que nacen en las bocas del Atrato y en Vigía del Fuerte. Por la vía a Urrao conectaba al Bloque Noroccidental. Por el sur, vía Bagado e Ismina se conectaba con Caldas y el Tolima (Rovira, Ronsesvalles, Planadas y/o Marquetalia), por allímismo se salía al Valle por Pradera y Florida o hacia el sur del país por Dolores, Alpujarra o Colombia (Huila), conectando con la Uribe y con el Meta. Asíse conectaban el Bloque Noroccidental, Bloque Central, Bloque Oriental y Bloque Sur entre si'”(MARÍN et al. 2016, pp. 75-76).
}

De allí que la historia del conflicto armado interno pueda contarse a través de estos corredores, y de las intencionalidades y apuestas que los grupos armados han desarrollado, ya que por medio de estos se comprende las particularidades y especificidades de cada región del país, dimensionando los recursos naturales en disputa, las posiciones estratégicas que se pretendían alcanzar, y las posibles relaciones de estos actores con otros sectores sociales, económicos y políticos. 
En las siguientes páginas me propongo explorar esta relación territorial del conflicto armado colombiano, focalizando en las tres regiones que fueron centrales para el propósito de las FARC que sustenta la tesis central de este documento.

Mapa 1. Corredor occidental

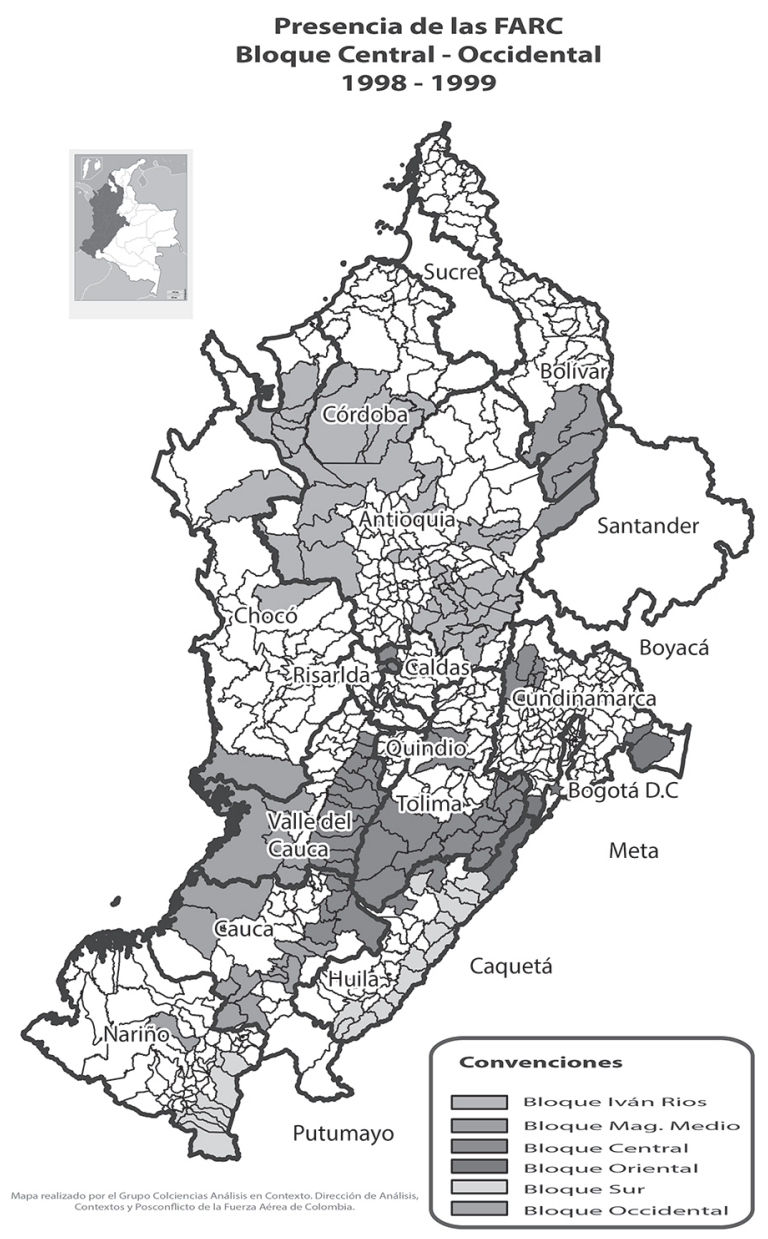

Fuente: Garzón, Daniel (2016)

El Mapa 1, sustenta la cita realizada en el libro de la DICOP; mostrando cómo la posición que asumen los Frentes de esta organización, en alineación con el Bloque Occidental, permitieron crear un corredor de movilidad que conectaba desde el departamento de Córdoba con los departamentos de Huila y Nariño, atravesando zona ricas en cultivos ilícitos y en recursos naturales.

Es sumamente enriquecedor para la comprensión de las acciones violentas que han asotado al sur del país, entender cómo los Bloques Central y Occidental de 
las FARC se estructuraron para generar una gran barrera de contención ubicada en el sur del departamento del Cauca. La detección de esta estrategia por parte del gobierno y de la Fuerza Pública, fue central para disminuir la presencia de esta organización en esta región (mayoritariamente indígena) y para liberar a la vía Panamericana del accionar irregular de este grupo armado (DAVILA, Gomis, \& SALAZAR, 2016).

Este movimiento, se sincroniza con las acciones que intentó desarrollar el grupo armado en el suroriente del país, en donde también despliega una ofensiva que buscaba conectar todos los Frentes y Bloques que operaban entre los departamentos que componen la Orinoquia colombiana:

“Así, para 1993, las FARC desarrollaron una serie de Frentes en la región: el 7, 42, 43, 26, 40 y el 31 se van a asentar en los municipios de Mesetas, Uribe, Puerto Rico, Vistahermosa, La Macarena, Puerto Lleras y San Juan de Arama; los frentes 22, 27 y 32 en la región del Sumapaz, al oriente del departamento de Cundinamarca; los frentes 31, 27, 38, 28, 10 y 45 se van a ubicar en el departamento de Arauca, abriendo una frontera con Venezuela, estratégica para sus fines económicos; los frentes 1, 7, 16, 39 y 44; se apoderaron de zonas tácticas en los departamentos del Guaviare, Vichada y Guainía” (Marín, et al. 2016, p. 101).

\section{Mapa 2. Corredor suroriental}

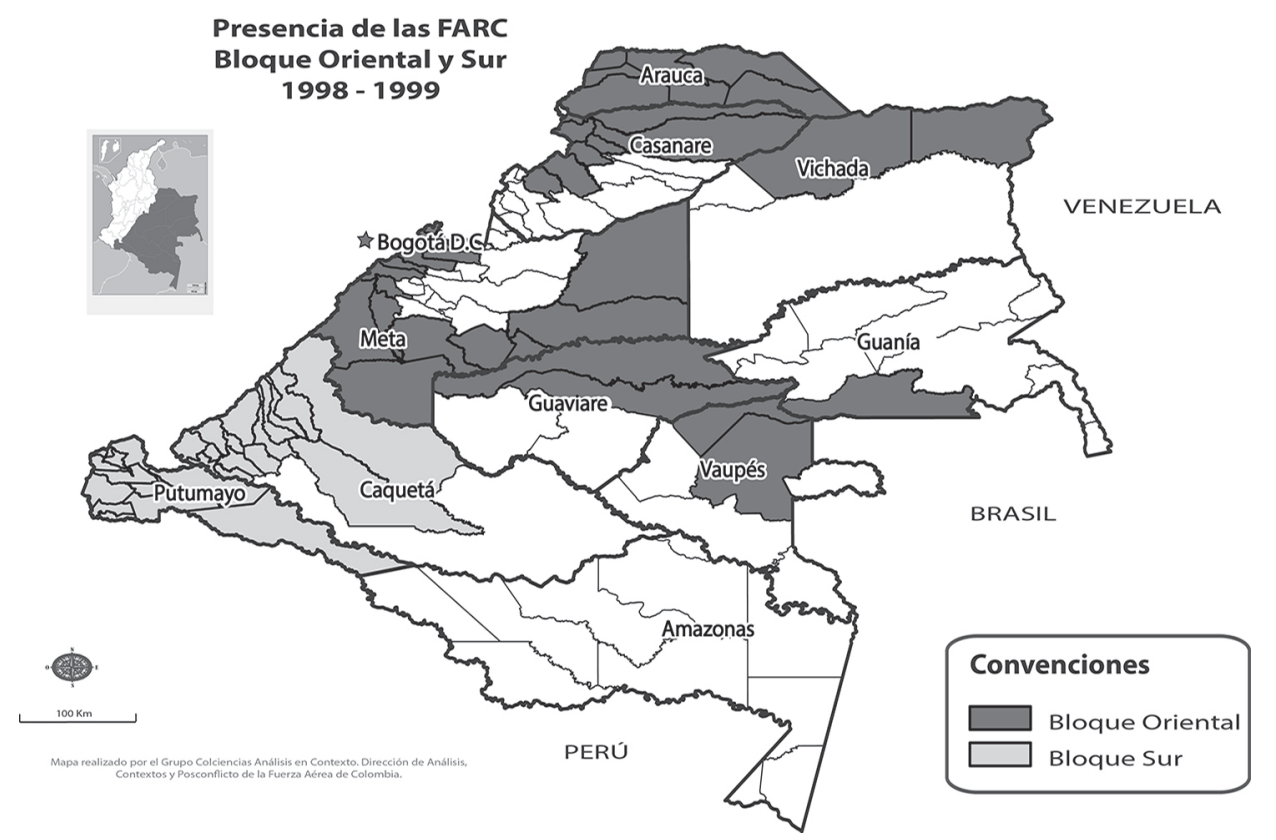

Fuente: Garzón, Daniel (2016) 
Si se sobreponen los dos mapas, se encontrará que había una clara intención por controlar una buena parte del territorio nacional, dividiendo a Colombia en dos, y aislando la zona sur del país, ganándose el control de las más grandes concentraciones de cultivos ilícitos del país, y teniendo acceso a las fronteras con Ecuador, Perú, Brasil y Venezuela, fundamentales para la entrada de armas y contrabando; y para la salida de narcóticos (ECHANDía \& BECHARA, 2006).

De hecho, el período en el que se desmilitarizó la región del Caguán (la Zona de Distensión), tiene que ser entendido bajo esta lógica; las FARC intentaron aprovechar ese territorio para ampliar su presencia en la región, apoderándose de una zona neurálgica de la Orinoquia, en inmediaciones de la capital de la República.

La intención de dar un uso táctico a la Zona de Distensión se evidenció con la escalada de acciones que las FARC realizaron en julio de 1999, con antelación al inicio de las negociaciones. En este momento, la ZD se utilizó como plataforma de los ataques hechos a los municipios ubicados en los alrededores. Estos ataques pusieron al descubierto el propósito de las FARC de avanzar en su «plan estratégico» mientras se llevaban a cabo las conversaciones con el gobierno. La escalada de la guerrilla buscaba, en primer lugar, ampliar el dominio territorial a partir de la ZD, donde concentró un componente de importancia histórica, y en segundo término, contribuir al desgaste del gobierno, que era blanco de fuertes críticas a causa del uso que las FARC le daban al escenario de las negociaciones. (ECHANDÍA, 2013, p. 55).

Así, la intervención oportuna de la Fuerza Aérea Colombiana y de las otras instituciones militares, tuvo que ser cortante y efectiva, para contrarrestar estos intentos irregulares que se dieron en el marco de un proceso de paz. La efectividad fue innegable, sobretodo si se tienen en cuenta diversos informes académicos que muestran que para los primeros años del Siglo XXI la presencia e influencia de las FARC era menor, y que habían perdido la capacidad de afectación a la población y a la infraestructura del Estado que otrora habían logrado desarrollar.

Así lo pone de presente la siguiente tabla construida por la Fundación Ideas para la Paz (2011) en la que se hace un análisis del Bloque Oriental de las FARC y de su presencia efectiva en la región:

Gráfico 1: Municipios con influencia de las FARC: 1992 - 2011

\begin{tabular}{|l|r|r|r|r|r|}
\hline & 1992 & 2002 & 2011 & 92 a 02 & 02 a 11 \\
\hline Número de municipios & 97 & 192 & 32 & $97,9 \%$ & $-83,3 \%$ \\
\hline Efectivos por municipio & 16,9 & 36,4 & 133,6 & 1,2 & 2,7 \\
\hline
\end{tabular}

Fuente: Fundación Ideas para la Paz (2013)

Para analistas como Camilo Echandía (2013) o el Observatorio de Derechos Humanos y DIH de la Presidencia de la República (2013), las FARC exedieron el límite de sus posibilidades al creer que podían mantener este control territorial por 
un largo período de tiempo; pero a su vez, reconocen que la intervención de la Fueza Pública fue fundamental para trastocar el ritmo que asumió el conflicto colombiano.

Es fundamental señalar en este punto, junto a Echandía (2013) y Esquivel (2016), que las posibilidades que le dio el poder aéreo a las Fuerzas Militares fue clave para llegar a las zonas más apartadas de la geografía nacional, en donde las FARC creyeron tener unos territorios propios, a los que no podría llegar nunca el Estado.

Desde que se desarrolló la Operación Colombia (1990) hasta Operaciones claves como la de Sodoma (2010) se lanzó un mensaje contundente a la opinión pública y a las organizaciones armadas: ningún territorio estaba vedado para la intervención de las Fuerzas Militares, y no existía ningún "santuario" de las FARC, o ninguna "República independiente", tal y como esta organización hacía querer suponer.

Pero lo más interesante de la intervención militar desarrollada, es que se impidió el plan final de esta organización: rodear a la ciudad de Bogotá, con el fin de intentar tomarse el poder por la vía armada, en un intento por destruir el Estado de derecho y la democracia colombiana (VALENCIA \& INSUASTY, 2011).

En el siguiente mapa, trato de mostrar esta tendencia, por medio de la presentación del movimiento que desarrolló las FARC, para ubicar Frentes en las inmediaciones de la capital, especialmente en la región del Sumapaz, en municipios de Cundinamarca y en las vías que comunicaban a Bogotá con Villavicencio.

\section{Mapa 3. Desplazamientos de las FARC (1998 a 1999)}

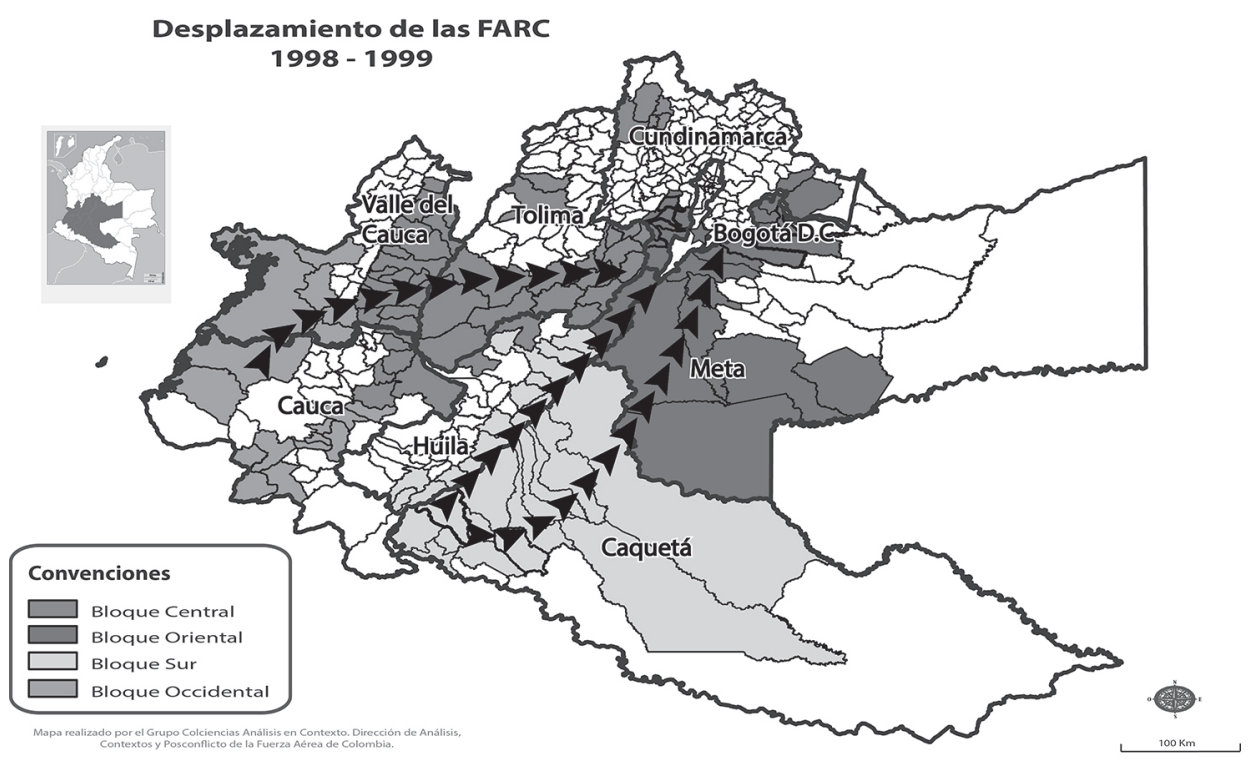

Fuente: Garzón, Daniel (2016) 
Sobra decir lo importante que fue impedir este movimiento de las FARC, y conmemorar el esfuerzo y sacrificio que significó repeler estas ofensivas violentas por parte de esta organización; pero también señalar que los indicadores de seguridad sobre el Sumapaz relevan que para el año 2005 ya no había una presencia significativa de hombres de este grupo en la región en mención, y que de hecho la presencia de las FARC en el departamento de Cundinamarca es muy baja, siendo éste uno de los cinco departamentos con menos número de acciones violentas por cuenta del conflicto armado interno (Observatorio del Programa Presidencial de Derechos Humanos y DIH, 2015).

\section{Transformaciones en las políticas de seguridad en Colombia en la década del noventa}

En la decada de los años ochenta, con la puesta en marcha de la Séptima Conferencia de las FARC (1983), se definen los lineamientos políticos y militares de la organización ilegal, según PIZARro "esta le da al movimiento una clara concepción operacional y estratégica como ejército revolucionario, lo que marcó un reajuste de todos sus mecanismos de dirección y mando." (PIZARRo, s.p, p. 188) Así mismo, es bajo este contexto que las FARC deciden cambiar su modo de operar, bajo el Plan Cisne 3 el cual consistía en la ubicación, asedio, asalto y copamiento de unidades militares. De esta manera, las FARC empiezan a proyectar desde los años ochenta su guerra irregular, bajo la concepción de la guerra popular prolongada.

Para entender la estrategia de las FARC, es necesario partir de la premisa que sus objetivos militares y políticos están alineados y funcionan bajo una lógica de inter acciones que apuntan a un solo fín. Esto según la premisa de Vicente Torrijos quien afirma que:

"La sincronización que hacen las FARC entre lo político y lo militar es la clave para entender cómo es que pretenden hacerse al poder o influir decididamente en él. Esa sincronización conduce a la idea de que lo político y lo militar no van en paralelo,como dos líneas cercanas pero que nunca se tocan. No. En realidad, lo político y lo militar se hallan fundidos en una lógica de interacciones sirviendo al mismo fin que no es otro que acceder al poder mediante un proceso revolucionario." (ToRRIJOS, 2009, p. 176).

En el contexto de las Fuerzas Militares, a finales de los años ochenta, se produce un cambio en la estrategia y la doctrina de las instituciones castrantes, en donde estas van a prepararse para la guerra irregular. De esta manera, en el año 1987 se "propició la creación y activación de los llamados Batallones de Contraguerrilla y el cambio de la preparación de los oficiales con un marcado énfasis al combate irregular, la nueva estrategia de las FARC volvería a señalar el cambio tanto en la conformación del Ejército..." (Del Valle, 2015, p. 9). Así mismo, es bajo este contexto que nace la 
Brigada Móvil No. 1, en donde se evidencia cómo las Fuerzas Militares cambian su estrategia militar para adecuarse al nuevo ambiente operacional. Sin embargo, cuando se produce este cambio, y siguiendo los lineamientos de la Séptima Conferencia, "se inicia un vertiginoso crecimiento de las FARC" (PIZARro, s.p) Por otro lado, "a mediados de la década y para enfrentar las acciones guerrilleras poco a poco fue surgiendo el concepto de apoyo mutuo entre el Ejército, la Armada y la Fuerza Aérea" (Río, 2008, p. 346). Esto porque anteriormente, no había un trabajo conjunto entre las Fuerzas Militares.

Ahora bien, con el gobierno de Cesar Gaviria, la situación de seguridad y defensa cambió, ya que durante este gobierno se evidenció una voluntad política para acabar con los grupos armados ilegales. El contexto político durante esta época estuvo caracterizado por una maniobra política y militar que estaba enfocada en la estrategia nacional contra la violencia y la política de negociación. Dentro de estas estrategias dos hechos marcaron la dinámica del conflicto armado colombiano, los cuales fueron el ataque a Casa Verde mediante la Operación Colombia, y la elección de los miembros de la Asamblea Constituyente; lo cual indicaba que el sistema político colombiano se estaba transformando.

\begin{abstract}
"Durante el primer semestre de gobierno ocurrieron dos acontecimientos que marcaron una coyuntura que permite descifrar la lógica subyacente en la evolución del conflicto armado colombiano al comienzo de la última década del siglo pasado. En efecto, en la madrugada del 9 de diciembre de 1990, se inició la operación militar sobre Casa Verde, sitio donde estuvo ubicado el cerebro dirigente de las FARC, desde 1983, ejerciendo un status político de hecho y al mismo tiempo se abrieron las urnas para elegir popularmente a los miembros de la ANC (Asamblea Nacional Constituyente)". (VELASQUeZ, 2006).
\end{abstract}

De esta manera, el Gobierno Nacional mostró la voluntad política de atacar al Secretariado de las FARC, utilizando sus capacidades militares tanto aéreas como terrestres. Este hecho generó un precedente ya que el Estado Colombiano mostró una iniciativa estratégica al atacar un centro de gravedad de la guerrilla, que en este caso era el Secretariado. "Por medio de inteligencia se prepara para un plan maestro que pretendía acabar con el corazón de las guerrillas como lo fue la operación Colombia con el fin de atacar la Uribe y el secretariado de las FARC (...) dicho ataque se preparó con antelación y se utilizó por primera vez un contingente de todas las aéreas, infantería, fuerza aérea, helicópteros helicoportados, y contrainsurgencia." (VALENCiA \& InSUASTY, 2011). Otro hecho generado a partir de la Operación Colombia, radica en que después de la operación, las FARC solicitan iniciar las conversaciones de paz con el Gobierno, lo cual demuestra como una operación militar altera el contexto político del Estado. "Es necesario generar previamente un entorno o contexto político militar que induzca la merma en la intensidad del conflicto, para hacer más viable la negociación." (VelasqueZ, 2006, p. 159). Sin embargo, cuando solicitan esta 
petición al Gobierno en el transcurso de 72 horas después de ese 9 de diciembre de 1990, las FARC se repliegan. De esta manera, si la ofensiva de las Fuerzas Militares hubiera continuado, muy seguramente la organización hubiera quedado aún más debilitada. Empero, como las Fuerzas Militares siguen las directrices y las instrucciones del Presidente de la República, quien tiene la responsabilidad de mando como comandante en jefe de las Fuerzas Militares, para ese momento no se tenía permitido ni siquiera prender los helicópteros.

Después de Casa Verde, Según Echandía “la organización insurgente logró avanzar en el proceso de especialización de sus frentes y la creación de grupos de choque, como las columnas móviles." (Echandía \& BECHARA, 2006).

Así mismo, "la administración de Gaviria, buscó marcar un cambio en relación con las Fuerzas Armadas: "Inicia su gobierno con unas políticas más claras y parece apuntar a un control civil del orden público, por primera vez en el país, asumiendo la responsabilidad que le compete al Estado en el manejo de estos asuntos." (VARGAS, 2002, p. 73). Como política de seguridad del Gobierno, Gaviria creó la Estrategia Nacional de Violencia, según Francisco Leal "la estrategia reconoció la multiplicidad de formas de violencia, incluida la producida por el Estado". Hizo un importante esfuerzo por identificar las principales relaciones sociales de este fenómeno y formuló un tratamiento para cada una de sus manifestaciones, que involucraba al conjunto del Estado." (LEAL, 2002). Esto refuerza la tesis de la voluntad política del Gobierno para mejorar las condiciones de seguridad del país, en donde primero se constituye una política de seguridad, se mejoran las relaciones cívico-militares, y se genera un contexto político para un proceso de paz. "Según la Estrategia, para erradicar el flagelo de la violencia era indispensable hacer compatibles los objetivos generales con las particularidades regionales. Para ello era necesario comprometer a los gobernadores, los alcaldes y los consejos seccionales y departamentales de seguridad, y contar con la opinión de todos los sectores de la población." (Leal, 2002, p. 82). En ese sentido se evidencia como el Gobierno Nacional quería articular la política de seguridad con las políticas económicas y sociales teniendo en cuenta el enfoque territorial, como manera de enfrentar los factores que causaban violencia en el país.

Así mismo, según lo señala CRUZ se produjo un "crecimiento de la guerrilla, derrotando la concepción de guerra integral, sirvió para que Gaviria acentuase la visión militar, se dieron todas las garantías, recursos y manos libres a las Fuerzas Armadas." (CRUZ, 2001, p. 227).

Por otro lado, Gaviria implementó una política de paz, "En este período culminaron las negociaciones con el EPL, el Quintín Lame y el PRT. (...). En este mismo contexto se inició un proceso de conversaciones con los alzados en armas que formaron parte de la coordinadora guerrillera Simón Bolívar y que se llevó a cabo en Caracas, Venezuela y Tlaxcala, México. El modelo de negociación 
que propuso el gobierno de Gaviria a las FARC y el ELN es el mismo esquema que se adoptó con el M19. A pesar de emplear la acción militar como una forma de ganar peso en las negociaciones, la FARC y el ELN discutirían, en su seno, la validez de la lucha armada" (LoPEZ, 1999, p. 253).

Ahora bien en cuanto a la dinámica del conflicto armado, "los combates por iniciativa de las Fuerzas Militares incrementaron en virtud de la llamada "guerra integral contra la guerrilla" lanzada tras el fracaso de los diálogos de paz con la Coordinadora Guerrillera Simón Bolívar (CGSB). La proporción entre los combates iniciados por las Fuerzas Militares y las acciones de las FARC aunque siguió siendo desfavorable al Estado, mejoró ostensiblemente.” (EchANDÍA, 2011, p. 8).

En ese sentido, el Gobierno de Gaviria implementó una táctica de seguridad mediante la implementacion de la Estrategia Nacional contra la Violencia, la cual se constituyó como la política de seguridad del Gobierno. Así mismo, con la Operación Colombia demostró la voluntad política y la iniciativa estratégica para atacar a la organización ilegal, hecho que se marcó como un punto de inflexión del conflicto armado colombiano, por la alteración de las dinámicas propias del conflicto. Esto porque demostró que el Estado es quien debe ostentar el monopolio legítimo de la violencia, el cual tiene unas instituciones militares encargadas de la seguridad y defensa del Estado y la Nación. Así mismo, esta operación demostró que las Fuerzas Militares pueden trabajar conjuntamente, generando precedentes posteriores.

Durante la presidencia de Ernesto Samper, la situación de orden público en el país se ve fuertemente afectada por el incremento de los ataques de los actores armados ilegales, como los efectuados por las FARC con Las Delicias, El Billar, Miraflores,Patascoy y Mitú. "las FARC durante el gobierno de Ernesto Samper (1994-1998) buscaron mediante la ejecución de una serie de acciones contundentes desbordar la capacidad de reacción y contención de la Fuerza Pública." (Echandía, Camilo, 2011, p. 8). Estos ataques tuvieron un antecedente que fue la Octava Conferencia de las FARC, en donde las "FARC comienzan a concentrar un número enorme de su fuerza en el país." (PizARro, s.p, p. 188). Esto responde a la estrategia militar para descartar al Estado y las Fuerzas Militares tratando de dispersarlas. Así mismo las FARC empiezan a implementar una estrategia centrípeta, la cual consistía en "la creación de unidades militares capaces de cercar y aniquilar bases y tropas de élite del Ejército oficial, (...) la doctrina militar va a encontrar en este contexto un terreno apropiado para desplegar plenamente sus potenciales." (PIzARro, s.p, p. 188).

Según Echandía, "El balance de fuerza, que es desfavorable al Estado, tuvo el agravante de que la tendencia ascendente en los combates de las Fuerzas Militares con las FARC a partir del fracaso de las negociaciones en el Gobierno Gaviria, se invirtió a partir de mediados de 1997 cuando comienzan a caer en picada hasta julio de 1998." (2011). 
Así mismo, bajo este contexto y con la creación de las empresas de seguridad privada, las Convivir, las autodefensas ilegales empiezan a enfrentarse con la guerrilla "Los cambios experimentados recientemente también muestran cómo los grupos paramilitares (sic) se involucraron a partir de 1996 en la dinámica de la guerra y logran romper la retaguardia del ELN, que pierde hegemonía en una franja del territorio que abarca desde el nordeste antioqueño hasta Norte de Santander." (ECHANDÍA, 2004, p. 5).

De esta manera, el Gobierno Nacional demostró que no tenía la capacidad política y militar para enfrentar la amenaza que representaban las FARC para ese entonces, así como otros actores armados ilegales como eran las autodefensas. Esto también se vio perjudicado por el ambiente internacional, en donde la comunidad internacional veía el contexto colombiano con preocupación, hasta el punto de llegar a declarar a Colombia como Estado Fallido. "Uno de los ejemplos en el que un elemento exógeno aportó a la identificación de que Colombia estaba ad portas de constituirse en un "Estado fallido" fue el proceso anual de certificación de Estados Unidos en materia de lucha contra las drogas" (Tokatlian, 2008). Esto porque además durante el gobierno de Samper, con el proceso 8.000 el Estado Colombiano perdió credibilidad y legitimidad, afectando la seguridad y defensa, ya que por ejemplo los recursos en materia de cooperación militar disminuyeron. Esto perjudicó la acción de las Fuerzas Militares ya que no contaban con los recursos económicos para poder enfrentar la amenaza.

"La crisis moral y política del gobierno le resta legitimidad para imponer las condiciones a los militares y ofrecer suficientes garantías para el desarrollo de las negociaciones. La relación de tensión con los Estados Unidos en torno a la extradición de nacionales y las investigaciones adelantadas por la fiscalía a miembros de la campaña y del partido oficialista, derivó en una coyuntura de crisis política y baja credibilidad en el gobierno de turno." (LopEZ, 1999, p. 12).

Cuando inició el período presidencial de Andrés Pastrana (1998-2002), la dinámica del conflicto armado estaba caracterizada por los enfrentamientos que se realizaron entre la Fuerza Pública y la organización ilegal. Es, bajo este contexto, que en 1998 se produce la Toma de Mitú, la cual estaba enfocada a demostrar la capacidad militar y política de las FARC. Sin embargo, bajo la Operación Vuelo de Ángel las Fuerzas Militares recuperan la iniciativa estratégica, ya que demuestran que mediante la utilización del poder aéreo, estas pueden obtener la ventaja estratégica por las capacidades de reacción y apoyo aéreo.

Además, esta operación logró alterar la estrategia de las FARC, ya que las obligó a retroceder a la guerra de guerrillas, esto porque con los ataques al Billar y Mitú implicaba la concentración de guerrilleros en unidades de masa, las cuales quedaban expuestas al poder aéreo. "La Operación Vuelo de Ángel marcó un punto de quiebre en el conflicto colombiano, porque esta operación 
frenó la avanzada guerrillera. Gracias al poder aéreo demostrado, se dieron de baja a muchos guerrilleros, lo cual permitió inclinar la balanza hacia el Estado Colombiano. Así mismo, con esta operación se alteró la correlación de fuerzas entre las FFMM y las FARC-EP.” (SANTOS, 2016, p. 136).

Por otro lado, el contexto político durante el Gobierno de Andrés Pastrana estuvo caracterizado por la transformación de las Fuerzas Militares, la cual se vio fortalecida por la implementación y consolidación del Plan Colombia. Esto porque el Plan le otorgó a las Fuerzas Militares mejores recursos tecnológicos para poder operar. Por ejemplo, "los fondos destinados para la asistencia militar 328 millones (63,2 \%) son para comprar helicópteros (208 para Black Hawks y 120 para Hueys)" (LeAL, 2002, p. 181). Esto alteró la dinámica del conflicto armado y le otorgó a las Fuerzas Militares la capacidad militar ofensiva. De igual forma, el Plan Colombia fue la reacción del Estado frente a una amenaza, en donde la política exterior sirvió para la seguridad del Estado. "El PC estableció el marco institucional de cooperación bilateral entre el Gobierno de los Estados Unidos y el Gobierno de Colombia para: i) fortalecer las capacidades operacionales de la Fuerza Pública contra la cadena de producción del narcotráfico y la lucha contra los Grupos Armados al Margen de la Ley (GAML)." (DNP, s.p) En ese sentido, el Plan Colombia estaba enfocado en atacar las dos principales amenazas para el Estado representadas en el narcotráfico y los grupos armados al margen de la ley, mediante la repotenciación de las capacidades militares.

\begin{abstract}
"Adicional a la profesionalización, tres aspectos permiten visibilizar la modernización de la Fuerza Pública. En primer lugar, se presentó una mejor coordinación entre las FF.MM., a través de las fuerzas de tarea conjunta. En segundo lugar, el sector de Seguridad y Defensa sustituyó el armamento y material de guerra, fortaleció los sistemas de comunicaciones, planeación, investigación criminal, inteligencia y de equipo logístico. Y por último, la Fuerza Pública adquirió nuevas tecnologías ofensivas que permitieron neutralizar grandes concentraciones guerrilleras y mejorar los tiempos de respuesta ante acciones unilaterales de los GAML.” (DNP, s.p)
\end{abstract}

Este plan modificó las estructuras orgánicas de las Fuerzas Militares, ya que permitió la creación de nuevas estructuras militares, según el Departamento Nacional de Planeación en un documento realizado como balance del Plan después de 15 años , "Colombia pasó de tener menos de 35 helicópteros en 1999 a más de 200 en 2014; en el mismo período de tiempo, las brigadas móviles pasaron de 3 a 36 ; se crearon 8 batallones de alta montaña y 52 escuadrones móviles; el 100\% de sus miembros han sido capacitados en derechos humanos y Derecho Internacional Humanitario.” (DNP, s.p). Esto marcó y alteró la dinámica de confrontación del conflicto armado colombiano, ya que le dio a las Fuerzas Militares, mayor 
capacidad y maniobrabilidad, recuperando así la iniciativa estratégica ${ }^{2}$. Por otro lado, el Plan Colombio le otorgó mayor versatilidad a las Fuerzas Militares, ya que les permitió operar y tener "disponibilidad 24/7 con cambios significativos en la capacidad de operación aérea y de combate" (DÁvila, Gomis, \& SALAZAR, 2016, p. 109). Esto porque con la adquisición de los visores nocturnos, se aumentó la capacidad para combatir a los actores armados ilegales durante la noche.

Según ECHANDía una de las consecuencias de la transformación de las Fuerzas Militares es que, "la reforma militar le dio al Estado nuevas capacidades para combatir a los grupos irregulares, impidió que las FARC avanzaran en su "plan estratégico" y utilizaran de manera táctica el escenario de las conversaciones como lo había propuesto el grupo guerrillero desde el momento en que creó la Zona de Distensión (ZD) en el área correspondiente a los municipios de San Vicente del Caguán en Caquetá y Uribe, Mesetas, Vistahermosa y La Macarena en Meta." (ECHANDía, 2011, p. 15).

De esta manera, mientras que se producía la transformación de las Fuerzas Militares, el Presidente Pastrana también optó por una negociación de paz con las FARC. "El pedido hecho por las FARC a comienzos de 1998, de desmilitarizar los municipios de San Vicente del Caguán, La Uribe, Mesetas, la Macarena, y Vista Hermosa, como requisito para iniciar conversaciones de paz, fue ratificado a mediados del año y aceptado por Pastrana" (LeAL, 2002). De esta manera, se estableció la zona de distensión, la cual tenía como objetivo facilitar las conversaciones. Sin embargo, las FARC aprovecharon la situación política para seguir violando los Derechos Humanos de la población civil, así como mantener y asegurar su estrategia de la toma del poder.

\begin{abstract}
"Al efecto la inteligencia aérea jugó un gran papel en la obtención de información confiable que llevaron al Ejecutivo a decidir la suspensión del diálogo de paz y recuperar la zona de distensión (Comando Aéreo de Combate No. 1-CACOM-1, 2002). Información que constató las vías terrestres de acceso, pistas de aterrizaje ilegales, infraestructuras para mantenimiento y resguardo de transporte vehicular, crecimiento de los cultivos de coca, relaciones con terroristas internacionales en la zona despejada y, además, la continuación de atentados terroristas, secuestros y ataques a poblaciones." (Marín, Castiblanco, Castrillon, y Cotrina, 2016, p. 105).
\end{abstract}

En ese sentido, con la retoma de la Zona de Distensión, con la transformación militar y el Plan Colombia, las Fuerzas Militares demostraron que el Estado Colombiano tenía las capacidades militares para recuperar los municipios de la Zona de Distension, al igual que se evidenció la iniciativa estratégica del Alto Gobierno.

Por otro lado, dentro de las adquisiciones del Plan Colombia se encuentran la compra de "H-1N Huey Helicópteros,50 UH-II Huey-II Helicópteros,20 UH-60 Black Hawk Helicópteros, Un número no determinado de misiles dirigidos (bombas inteligentes), 13 AT-802 aeronaves de fumigación 11 OV10, aeronaves de fumigación • 1 T-65 aeronave de fumigación, Caravan (transporte aéreo), Aviones no tripulados." (DNP, s.p). 
Con el Gobierno del Presidente Uribe, se creó la Política de Seguridad Democrática, la cual establecía que "La Fuerza Pública iniciará el proceso de consolidación del control estatal sobre el territorio, asegurando su presencia permanente y definitiva en todas las cabeceras municipales, con el apoyo de brigadas móviles y demás unidades de las Fuerzas Militares y de la Policía Nacional.” (Presidencia de la República, 2003, p. 16).

Producto de la conduccion estratégica del Estado en materia de seguridad y defensa, durante el Gobierno de Uribe, como lo evidencia ECHANDÍA, se alteró nuevamente la estrategia de la guerrilla:

\begin{abstract}
"A partir de 2002 es posible observar un cambio en las estrategias y los movimientos tácticos de los alzados en armas, en función de las modificaciones en la dinámica de la confrontación. La decisión del gobierno de Álvaro Uribe de enfrentar el desafío de la guerrilla con un mayor esfuerzo militar sobre las estructuras armadas ha hecho que retomen de su experiencia anterior los comportamientos propios de la guerra de guerrillas y opten por el repliegue táctico hacia sus zonas de refugio, lo cual se expresa en una disminución operativa a nivel nacional." (ECHANDÍA \& BECHARA, 2006, p. 37).
\end{abstract}

Igualmente, dentro de la política de seguridad democrática se establecieron como amenazas el terrorismo, las drogas ilícitas, las finanzas ilícitas, el tráfico de armas, municiones y explosivo, el secuestro y la extorsión, el homicidio. (Presidencia de la República, 2003).

Teniendo en cuenta las dinámicas del conflicto, en el 2004 se crean las Fuerzas de Tarea Conjunta,como respuesta para afrontar el problema de seguridad y defensa que representaban en ese momento las organizaciones ilegales como las FARC. "Fue así como en el año 2004 se produce una de las mayores trasformaciones en la historia de las Fuerzas Militares de Colombia, creando unidades conjuntas que hoy, aunque con modificaciones de enfoque, siguen expandiéndose en el país y dando resultados valiosos para la recuperación de la seguridad en puntos críticos de la geografía nacional.” (FLóREz, 2012, p. 54). Estas Fuerzas de Tarea Conjunta buscaban articular las capacidades del Ejército Nacional, la Armada y la Fuerza Aérea, mediante la focalización y la acción conjunta.

Se da entonces como premisa de la Política de Seguridad, como lo afirmó Marta Lucía Ramírez en la carta de presentación de la política, "La Fuerza Pública dará el primer paso en este esfuerzo de articular una respuesta integral a los retos de seguridad. El segundo lo debe dar el Estado en su conjunto y el tercero, toda la sociedad." (Presidencia de la República, 2003, p. 8). Esto significaba que la concepción de seguridad iba más allá de tratar el problema con la organización ilegal FARC y otros actores armados, la seguridad debía consolidarse también con otras instituciones del Estado y contar con la participación y apoyo de la población civil. De esta manera, es bajo el Gobierno del Presidente Uribe que se 
puede afirmar que el famoso tríangulo de Clausewits, Estado, Población y Fuerzas Militares se completa, ${ }^{3}$ esto porque por la política de seguridad y los resultados operacionales, la población civil se da cuenta que las Fuerzas Militares estaban recuperando el territorio.

Esto se demuestra con la implementación de diferentes planes como el Plan Patriota, el cual tenía como objetivo la recuperación territorial de unos departamentos:

“La favorabilidad militar del Estado (...) se acentúa durante este período en el marco de la Política de Seguridad Democrática del ex presidente Álvaro Uribe (2002-2010) gracias a la implementación de planes de recuperación territorial como el Plan Patriota en 2004 con énfasis en Meta, Guaviare y Putumayo, los Planes Libertad I y II (en 2003 y 2005) en Cundinamarca y Tolima; la operación Marcial en el Oriente antioqueño y otras operaciones en las zonas de Montes de María y Arauca." (Prieto, Rocha, \& Marín, Seis tesis sobre la evolución reciente del conflicto armado en Colombia, 2014).

De esta manera, puede afirmarse que la Política de Seguridad Democrática, "se construyó sobre un conjunto integral de estrategias que incluían el control del territorio y la defensa de la soberanía, la desarticulación de los GAI y de las organizaciones dedicadas a la producción y tráfico de drogas, el fortalecimiento del servicio de justicia y la atención del Estado en zonas deprimidas y de violencia." (RENTERÍA, 2008, p. 4). Dentro de los logros obtenidos de la Política se encuentra "la neutralización de los frentes guerrilleros que rodeaban a Bogotá, la desarticulación de las milicias que operaban en la capital antioqueña y, en general, el profundo debilitamiento de las estructuras armadas de la insurgencia." (RENTERÍA, 2008, p. 5). Durante el período 2003-2009 hubo una disminución del conflicto por la política de seguridad del Gobierno Uribe, esto según una investigación realizada por la Universidad del Norte. (Universidad del Norte, 2016, p. 2).

Ahora bien, después de la reelección del Presidente Álvaro Uribe, se establece la Política de consolidación de Seguridad Democrática, la cual "se fundamenta en la articulación institucional de las diferentes entidades del Estado, en el esfuerzo militar y policial, el apoyo de la población civil y la cooperación internacional." (RENTERÍA, 2008). Esta buscaba reforzar y articular las acciones de las instituciones del Estado, para solucionar el problema de seguridad integralmente, y no solo bajo el liderazgo de las Fuerzas Militares. De aquí que "para alcanzar el objetivo de consolidación, el Plan Nacional de Desarrollo 2006-2010 plantea tres estrategias fundamentales: el control del territorio y defensa de la soberanía nacional, el combate al problema de las drogas ilícitas y al crimen organizado, y el fortalecimiento de las políticas de convivencia y seguridad ciudadana." (RENTERÍA, 2008, p. 7).

Según Clausewits, la trinidad de la guerra está compuesta por el pueblo, el segundo, al comandante en jefe y a su ejército, y el tercero, solamente al gobierno (2003). 
Por otro lado, con las Políticas de Seguridad del Gobierno Uribe, la dinámica del conflicto armado interno cambió y trajo como resultado que:

“1) En 2007 se llegó al pico en los combates por iniciativa del Ejército de los 25 años estudiados; 2) En 2008 el accionar armado de las FARC disminuyó significativamente en comparación con la situación de 2003; 3) las FARC, debilitadas, se replegaron hacia zonas fronterizas como Putumayo, Nariño, Cauca, Catatumbo en Norte de Santander y Arauca, y 4) las FARC perdieron su capacidad para cometer grandes ataques a poblaciones e instalaciones militares, por lo que enfocan su accionar en eventos que requieren de poca movilización de personal y recursos.” (Prieto, Rocha, \& Marín, 2014, p. 10).

Durante el 2008-2010, "las ofensivas desarrolladas por la fuerza pública continuaron siendo superiores a la actividad armada de las FARC, a lo que se suman los esfuerzos del Estado por dar con el paradero de los comandantes de bloques y frentes más importantes de la agrupación (PRIETO, RochA, \& MARÍN, 2014). Desde el Ejecutivo se evidenciaba una política dirigida contra las FARC, y la focalización de la estrategia de seguridad, mediante los objetivos transcendentales de alto valor, que dieron como resultado bajo la operación Sodoma, la muerte de Jorge Briceño, alias el Mono Jojoy; esto va a alterar la táctica de las FARC, en la medida en que se impacta un objetivo de alto valor. Por otro lado, las FARC, "para contrarrestar su debilitamiento, en 2008 (...) ponen en marcha el Plan Renacer que bajo un principio de economía de la fuerza, logra aumentar levemente su iniciativa armada con la activación de artefactos explosivos, hostigamientos, ataques con francotirador y contra la infraestructura económica." (Prieto, Rocha, \& MARÍn, 2014, p. 11).

\section{CONCLUSIONES}

Este documento evidencia las transformaciones en el terreno de la seguridad que experimentó Colombia en la década de los años noventa, gracias al desarrollo de políticas de seguridad de Estado, integrales y con el apoyo de la cooperación internacional; y al enorme sacrificio que los miembros de la Fuerza Pública desplegaron para garantizar la tranquilidad de la sociedad.

Así, en la primera parte del documento, quedó evidenciado que el conflicto colombiano debe ser entendido y dimensionado de forma territorial, entendiendo las particularidades de cada región del país, y la de los grupos específicos que operan en cada uno de estos territorios. Ello podría llevar a señalar que aunque los actores armados tienen una estructa jerárquica que impone unos lineamientos comúnes (por ejemplo alinear a las FARC para acercarse a la capital), en el fondo cada región experimenta el conflicto de una forma específica y diferenciada. 
Durante todos los años de servicio, evidencié los cambios que se presentaron en el conflicto colombiano, y fui testigo de los momentos más cruentos de la violencia que azotó al país; pero también tuve la suerte de hacer parte de la Fuerza Aérea Colombiana, y de experimentar las transformaciones de seguridad que el actuar de las instituciones militares le dieron al país.

Estas transformaciones están ampliamente documentadas en cifras oficiales y en reportes académicos, así que el plusvalor (uno de ellos) de esta investigación está en detallar las estrategias de movilidad que quiso desarrollar las FARC, y en evidenciar cómo fueron repelidas y desbaratadas todas ellas.

El lector encontrará una cartografía del conflicto armado colombiano, en la que se representan los corredores estratégicos que se quisieron configurar durante la década del noventa; corredores que desembocaban en Bogotá, pero que a la vez eran utilizados como rutas para la entrada de armas y la salida de drogas.

En ese contexto, también se experimentaron oscilaciones en las políticas de seguridad que cada gobierno desarrolló, con directas consecuencias sobre la dinámica del conflicto armado colombiano. Estas políticas, a su vez, estuvieron alineadas con las doctrinas de seguridad que emanaron del ambito internacional, y lograron que en un momento particular se configuraran armoniosamente, a través, por ejemplo, del Plan Colombia, y de los valiosos recursos de inversión que con éste entraron al país.

Así se teje la última conclusión de este documento: no es posible lograr victorias decisivas en el marco del conflicto armado interno, si no hay una plena articulación entre el poder político (Ejecutivo) y el poder militar. Para las Fuerzas Militares es fundamental y gratificante, trabajar de la mano con gobiernos que son dolientes del tema de la seguridad y que apoyan irrestrictamente a sus Fuerzas en el camino por labrar la paz del país.

\section{REFERENCIAS}

\section{Capítulos de libro}

Dávila, A., Gomis, M., \& Salazar, G. (2016). el Conflicto en Contexto 19982014. En A. Dávila, G. SAlazAR, \& A. GonzÁlez, El conflicto en contexto: un análisis en cinco regiones colombianas 1998-2014. Bogotá: Editorial Universidad Pontificia Javeriana.

LEAL, F. (2002). Nuevos temas para la agenda de seguridad nacional gobierno de Cesar Gaviria Trujillo, 1990-1994. En F. L. BuITRAGo, La seguridad nacional a la deriva: del Frente Nacional a la posguerra fría. Bogotá: Alfaomega.

Marín, A., Castiblanco, C., CAstrillon, J., \& Cotrina, A. (2016). La zona de distensión y su recuperación por la Fuerza Aérea Colombiana. En R. 
Esquivel, A. Marín, C. Castiblanco, J. Castrillón, A. Cotrina, M. SanTOS, . . J. GARCÍA, La Fuerza Aérea Colombiana y el término del conflicto armado:Victorias desde el aire. Bogotá: Impress Colombia.

Clausewits, K. (2003). De la guerra. Obtenido de El Cid Editor : http://lahaine. org/amauta/b2-img/Clausewitz\%20Karl\%20von\%20-\%20De\%20la\%20 guerra.pdf

Cruz, A. (2001). El dilema de la paz: renuncia a las armas o reformas estructurales. En J. M. Manuel Alcántara, Colombia ante los retos del siglo XXI: desarrollo, democracia y paz. Salamanca: Universidad de Salamanca.

Del VAlLe, W. (2015). Perfil del oficial del ejército en el postconflicto. Obtenido de Universidad Militar Nueva Granada: http://repository.unimilitar.edu.co/ bitstream/10654/13563/1/PERFIL\%20DEL\%20OFICIAL\%20DEL\%20 EJ\%C3\%89RCITO\%20NACIONAL\%20EN\%20EL\%20POSTCONFLICTO.pdf

DNP. (s.p). Departamento Nacional de Planeación. Obtenido de Plan Colombia: Balance de los 15 años: https://colaboracion.dnp.gov.co/CDT/Sinergia/ Documentos/PLAN_COLOMBIA_Boletin_180216.pdf

ECHANDÍA, C., \& BeChARA, E. (2006). Conducta de la guerrilla durante el gobierno Uribe Vélez: de las lógicas de control territorial a las lógicas de control estratégico. Análisis Político(57).

ECHANDÍA, C. (2004). La Guerra por el Control Estratégico en el Suroccidente Colombiano. En Revista Sociedad y Economía(7).

ECHANDÍA, Camilo. (2011). Situación actual de las FARC: Un análisis de los cambios en las estrategias y la territorialidad (1990-2011). Obtenido de Fundación Ideas para la Paz: www.ideaspaz.org/publications/posts/78

Flórez, J. (2012). La doctrina conjunta en Colombia: análisis de la fuerza de tarea conjunta omega. Obtenido de Universidad Nacional de Colombia: http://www.bdigital.unal.edu.co/7724/1/699243.2012.pdf

LEAL, F. (2002). Nuevos temas para la agenda de seguridad nacional gobierno de Cesar Gaviria Trujillo, 1990-1994. En F. L. Buitrago, La seguridad nacional a la deriva: del Frente Nacional a la posguerra fría. Bogotá: Alfaomega.

LóPez, W. (1999). Las políticas de paz y los procesos de negociación en colombia. breve balance y perspectivas. En: Revista Convergencia.

PizARRo, E. (s.p). Las FARC-EP ¿Repliegue estrategico, debilitamiento o punto de inflexión? . En E. Pizarro, Las FARC-EP ¿Repliegue estratégico, debilitamiento o punto de inflexión? Bogotá. 
Presidencia de la República . (2003). Politica de Defensa y Seguridad Nacional. Obtenido de Organizacion de Estados Americanos: www.oas.org/csh/spanish/documentos/colombia.pd

Prieto, C., Rocha, C., \& Marín, I. (2014). Fundacion Ideas para la Paz. Recuperado el 13 de julio de 2016, de Seis tesis sobre la evolución reciente del conflicto armado en Colombia: http://cdn.ideaspaz.org/media/website/ document/5436b8cdbf6e1.pdf

Prieto, C., Rocha, C., \& Marín, I. (2014). Seis tesis sobre la evolución reciente del conflicto armado en Colombia. Obtenido de Fundación ideas para la paz: cdn.ideaspaz.org/media/website/document/5421e84004722.pdf

ReNTERÍA, C. (2008). La Consolidación de la Política de Seguridad Democrática en el Plan Nacional de Desarrollo 2006- 2010. En: Revista Fuerzas Armadas Escuela Superior de Guerra: http://www.cgfm.mil.co/documents/10184/24774/ edicion+205.pdf/68c91 add-7eae-4a1d-8e32-643fca307ddc

Río, C. T. (2008). Conflicto interno y Fuerzas Armadas Colombianas 1982-2002. En

C. T. Río, De milicias reales a militares contrainsurgentes la institución militar en Colombia del siglo XVIII al XXI . Bogotá: Editorial Pontificia Javeriana.

Santos, M. A. (2016). La operación Vuelo de Ángel,punto de inflexión del conflicto armado colombiano. En Esquivel, C. Castiblanco, A. Marín, J. Castrillón, A. Cotrina, M. Santos, . . . J. García. La insistencia de las FARC en los ataques contra las instalaciones de la Policía Nacional a partir de 1997 se convirtió en todo un propósito estratégico inscrito en el desarrollo de planes de guerra dispuestos a lograr el control de zonas especificas cada. Bogotá: Impress Colombia.

Tokatlian, J. (2008). La Construcción de un "Estado Fallido" En La Política Mundial: El caso de las relaciones entre Estados Unidos y Colombia. Análisis Político, 21(64).

Torrijos, V. (2009). El poder y la Fuerza.En la unidad político-militar está la verdadera capacidad estratégica de la organización armada. En V. Torrijos, Crisis, Paz y Conflictos. Bogotá: Editorial Universidad del Rosario.

Valencia, J., \& Insuasty, A. (2011). Evolución de las estrategias de guerra en Colombia: ¿Cómo han evolucionado las estrategias de guerra utilizadas por el ejército colombiano en la historia de Colombia, 1 desde 1930 hasta 2006. El Ágora USB, , 11(1).

VArgas, A. (2002). Las Fuerzas Armadas colombianas y las concepciones de seguridad y defensa. En A. VARgas. Las Fuerzas Armadas en el conflicto colombiano: antecedentes y perspectivas. Bogotá: Intermedio. 
Velásquez, C. A. (2006). El ambito político en el conflicto armado con las FARC:1990-2006. En: Revista de Relaciones Internacionales, Estrategia y Seguridad, 1(2). 